\title{
Life Skills Through School Sport: A Participatory Teacher Development Program
}

\author{
Julie Vang Knudsen1,2, Lise Maria Elkrog-Hansen ${ }^{1,2}$, Lars Breum Christiansen ${ }^{1,2}$ \\ ${ }^{1}$ Department of Sport Science and Clinical Biomechanics, University of Southern Denmark, Odense, Denmark \\ ${ }^{2}$ Research and Implementation Centre for Human Movement and Learning, Odense, Denmark \\ Email: lbchristiansen@health.sdu.dk
}

How to cite this paper: Knudsen, J. V., Elkrog-Hansen, L. M., \& Christiansen, L. B. (2020). Life Skills Through School Sport: A Participatory Teacher Development Program. Advances in Physical Education, 10, 293-310.

https://doi.org/10.4236/ape.2020.103024

Received: July 30, 2020

Accepted: August 25, 2020

Published: August 28, 2020

Copyright $\odot 2020$ by author(s) and Scientific Research Publishing Inc. This work is licensed under the Creative Commons Attribution International License (CC BY 4.0).

http://creativecommons.org/licenses/by/4.0/ (c) (i) Open Access

\begin{abstract}
School sport participation can promote life skills in children and youth, but teachers could use an explicit teaching approach to fulfil the potential. Therefore, we conducted a participatory teacher development program, which should promote students' life skills through school sport at three Danish boarding schools. The aim of this study is to present the program and the teachers' experiences with the explicit teaching approach and the development program itself. The study design is based on participatory action research and comprised four phases in which the teachers were involved in the design, planning, implementation and evaluation of a life skills course for their students. The evaluation was based on focus group interviews with the teachers involved. The teachers found it beneficial to work explicitly with life skills in school sport and stated that the program provided an opportunity to view their practice from a different perspective. Furthermore, they emphasized that school sport could readily be structured in ways that increase the student's development of life skills. At the same time, the teachers found the explicit teaching strategies challenging due to priority of time and difficulties connecting the sports practice to other life contexts. Finally, the teachers experienced positive and engaged students who most likely increased their understanding of life skills.
\end{abstract}

\section{Keywords}

Positive Youth Development, Coaching, Sport Academies, Sport Psychology, In-Service Education

\section{Introduction}

It is often stated that participation in sport can be used as a vehicle to foster positive psychological and emotional development in young people, and that this personal development can be applied in various non-sport settings (Danish, 
Forneris, Hodge, \& Heke, 2004; Gould \& Carson, 2008). This type of personal competencies, learned and used in different contexts, is often termed life skills, which can be defined as: "the skills that enable individuals to succeed in the different environments in which they live, such as school, home, and in their neighbourhoods" (Danish et al., 2004: p. 40). Life skills are often described as falling into overarching categories such as: interpersonal, behavioural, cognitive, intrapersonal and emotional skills. Within these categories are more specific life skills such as: teamwork, problem solving, communication, creativity, coping, etc. (Danish et al., 2004; Gould \& Carson, 2008; Turnnidge, Côté, \& Hancock, 2014; UNICEF, 2019). An essential aspect of a life skill development in sport is that it can only be considered a life skill, when it can be transferred from the sporting context to non-sport contexts (Gould \& Carson, 2008; Pierce, Gould, \& Camiré, 2017) This process is called transfer and Pierce et al. (2017) define it as follows: "The ongoing process by which an individual further develops or learns and internalizes a personal asset in sport and then experiences personal change through the application of the asset in one or more life domains beyond the context where it was originally learned."

How the learning and internalization transpires depends on several aspects e.g. the socio-cultural environment, coach characteristics, coaching strategies and the athlete's competences and previous experiences (Pierce et al., 2017). Life skills development can be approached either implicitly or explicitly (e.g. Holt et al., 2017; Turnnidge et al., 2014). Using an implicit approach the coach has a focus on developing sport specific psychosocial skills and is not intentionally focused on developing life skills and transfer (Bean, Kramers, Forneris, \& Camiré, 2018; Turnnidge et al., 2014). This strategy can promote life skills, but it will be more random (Bean \& Forneris, 2016; Camiré, Trudel, \& Forneris, 2009; Jones \& Lavallee, 2009). An explicit life skill approach entails that the coach provides the athletes with opportunities to engage in activities intentionally designed to develop such skills and to facilitate the transfer of these to other contexts. These activities involve discussing, reflecting and practicing life skills in and out of the sport context (Bean et al., 2018; Holt et al., 2017; Jacobs \& Wright, 2018; Turnnidge et al., 2014).

Explicitly development of life skills through sport participation is relevant in all coaching and teaching practices, but particularly potent settings are schools, colleges and academies, where young people participate in both sport and education, and especially if they reside at the schools and interact with the teachers and coaches in other life situations. The Danish Efterskole, a special type of boarding school, is such a setting. Students between $14-17$ years can voluntarily finish secondary school (grades 8 - 10) at these schools, where they live, eat and go to school for one or sometimes two years. At many schools there are a focus on the students' personal development and cultural interest e.g. sport, music and art. The schools have a long tradition in Denmark, with a focus like the Danish Folk High Schools: to provide life enlightenment, public enlightenment and democratic education. Approximately $20 \%$ of all Danish teenagers attend a Da- 
nish boarding school (Efterskoleforeningen, 2017) and nearly half of the schools have an extensive focus on sport, dance and/or outdoor recreation.

The purpose of this study is to get practical knowledge of how teachers could improve their practice to fulfil the potential for life skill development through school sport. We selected three Danish boarding schools with an extensive focus on sport as an ideal setting due to their commitment to life enlightenment and positive youth development through sport. A participatory teacher development program was designed and conducted, which should lead to implementation of activities explicitly promoting life skill development through school sport practice. In order to obtain sustainable change, the teachers had to be actively involved in the development of the life skill course in collaboration with the research team. Furthermore, the courses were realized and tested in practice with students to obtain evidence of the acceptability, feasibility and potential of the explicit approach. The specific research question for this study is: How does school sport teachers experience to be engaged in developing their own teaching practice to explicitly promote life skills development and transfer?

\section{Method}

\subsection{Settings and Participants}

Teachers from three Danish boarding schools participated in the development program. All three schools have an extensive sport profile and the students choose one main sport for the entire school year. Normally, they practice their main sport three to five times per week and participate in tournaments and/or events. Additionally, the students participate in other sports and physical activities.

The main sport is the starting point for development of the life skill course. The school's management teams selected two main sports for the development program in agreement with the involved teachers. The sports were: Rhythmic gymnastics, TeamGym ${ }^{1}$, Girls' soccer, Fitness and E-sport (Table 1). A total of 15 teachers were enrolled in the development program, and due to leave of absence and change in teacher staffing three teachers were replaced during the process. The teachers were between 24 and 53 years old and had different teaching experience ranging from newly appointed to more than 20 years of experience. Besides their experience as teachers they had additional experience as coaches in leisure time sports.

All participants received detailed oral and written information about the purpose of the study and the interviews. Each participant signed a written consent form before the interviews began. All participants' names and names of schools are anonymised in all documents and publications. The data was stored and treated in accordance to EU General Data Protection Regulation. Students were informed of the study and the life skill course prior to the implementation.

${ }^{1}$ In TeamGym athletes perform gymnastic skills as a team in three different disciplines: floor, tumbling and trampette. 
Table 1. Overview of main sports and participating teachers at the three schools.

\begin{tabular}{|c|c|c|}
\hline School & Main sport & Teachers \\
\hline \multirow{8}{*}{ A } & \multirow{3}{*}{ Rhythmic Gymnastics } & Female, 28 years $^{\text {a) }}$ \\
\hline & & Female, 23 years \\
\hline & & Female, 23 years ${ }^{\mathrm{b})}$ \\
\hline & \multirow{5}{*}{ TeamGym } & Female, 47 years \\
\hline & & Male, 44 years \\
\hline & & Male, 42 years \\
\hline & & Male, 31 years \\
\hline & & Male, 21 years \\
\hline \multirow{6}{*}{ B } & \multirow{4}{*}{ Girls Soccer } & Female, 43 years $^{\mathrm{a})}$ \\
\hline & & Female, 37 years $^{\mathrm{a})}$ \\
\hline & & Female 27 years $^{\text {b) }}$ \\
\hline & & Male, 35 years $^{\mathrm{b})}$ \\
\hline & \multirow{2}{*}{ TeamGym } & Male, 28 years \\
\hline & & Male, 25 years \\
\hline \multirow{5}{*}{$\mathrm{C}$} & \multirow{3}{*}{ Fitness } & Female, 50 years ${ }^{c)}$ \\
\hline & & Female, 48 years \\
\hline & & Male, 47 years \\
\hline & \multirow{2}{*}{ E-Sports } & Male, 39 years \\
\hline & & Male, 32 years \\
\hline
\end{tabular}

a) participated only in the design phase, b) participated not in the design phase, c) participated only the planning phase.

\subsection{Development Program Design}

The development program was designed using principles from participatory action research, with the aim of creating knowledge and practice development through a democratic and participatory approach (Bradbury, 2015; Kemmis, McTaggart, \& Nixon, 2014). This approach involves interacting with participants in a predesigned development process, which aims to disrupt their habitual thinking and engage them in experimenting with new ways of approaching practice (Lehmann, 2018). The development program provided no predetermined activities for the life skills course. The researcher delivered a thorough theoretical introduction to life skills based on best scientific practice. Teachers were continuously involved in the development program and thereby allowed extensive possibilities to shape the content of the life skills course based on their current practice and own ideas. The program consisted of four phases in line with action research literature: design, planning, implementation and evaluation. Knowledge and new practice are created throughout the different phases-building on experiences from previous phases (Coghlan \& Brannick, 2010).

\subsection{The Four Stages of the Development Program}

\section{1) Design phase}

A thorough literature review was conducted to identify the scientific knowledge useful to this context constituting the programs theoretical framework. The aim was to synthesize, and tailor available scientific knowledge based on the knowledge-to-action approach (Graham et al., 2006). 
Subsequently, the teachers participated in $1 \frac{1}{2}$ hour focus group sessions comprising a short introduction, questions, individual reflections, group exercises and discussions. The focus groups aimed to introduce the teachers to the life skills terminology, build a shared understanding, and identify relevant objectives for the program.

During the focus groups the teachers were introduced to titles of 30 different life skills and were asked to pick the most important ones for their students' and explain the content and why they had picked them. The purpose was to increase the relevance and letting teachers put their own words on life skills, which they later should integrate in their teaching practice. The focus groups were recorded, transcribed and analysed across the three schools to identify dominant life skill themes. Five themes emerged, which are presented in Table 2: responsibility, deliberate practice, dealing with hardship, self-consciousness, and proactive.

\section{2) Planning phase}

In the planning phase the teachers participated in a four-hour workshop, where they were presented to the five dominant life skill themes. They discussed the themes, and each main sport selected one for their upcoming training lessons. Rhythmic gymnastics, Fitness and TeamGym (School B) chose "Proactive"; TeamGym (School A) and E-sport chose "Deliberate practice"; and Girls' soccer chose "Dealing with hardship". Responsibility and self-consciousness were not selected.

Table 2. The five dominant life skill themes emerging from the first focus group.

\begin{tabular}{|c|c|c|c|}
\hline Theme & Related life skills & Description & Teacher quote \\
\hline Responsibility & $\begin{array}{l}\text { Responsibility } \\
\text { Teamwork } \\
\text { Respect }\end{array}$ & $\begin{array}{l}\text { Students should be accountable to the } \\
\text { group. They should respect diversity, } \\
\text { and support everyone to prosper. } \\
\text { They should take responsibility for } \\
\text { the community and themselves. }\end{array}$ & $\begin{array}{l}\text { "The positive social environment is, } \\
\text { first and foremost, about being able to } \\
\text { make each other better and respect } \\
\text { each other and be themselves." }\end{array}$ \\
\hline $\begin{array}{l}\text { Deliberate } \\
\text { practice }\end{array}$ & $\begin{array}{l}\text { Planning } \\
\text { Goal setting } \\
\text { Perseverance }\end{array}$ & $\begin{array}{l}\text { Students should be able to plan and } \\
\text { balance their time, so there is room for } \\
\text { friends, training, school and family. } \\
\text { They should set goals, make plans for } \\
\text { their fulfilment, and carry them out } \\
\text { with perseverance. }\end{array}$ & $\begin{array}{l}\text { "It is important that you fight for things } \\
\text { and not just zap in and out because you } \\
\text { just want something else or because } \\
\text { you lose interest." }\end{array}$ \\
\hline Self-consciousness & $\begin{array}{l}\text { Self-conscious } \\
\text { Decision making } \\
\text { Reflexive }\end{array}$ & $\begin{array}{l}\text { Students should be self-conscious and able } \\
\text { to reflect on their actions and personal } \\
\text { values. They should find their own way in } \\
\text { life, and not blindly follow other people. }\end{array}$ & $\begin{array}{l}\text { "We must try to define personal values } \\
\text { with the students, and how they can be } \\
\text { lived out through their actions" }\end{array}$ \\
\hline Proactive & $\begin{array}{l}\text { Initiative } \\
\text { Courage } \\
\text { Curious }\end{array}$ & $\begin{array}{l}\text { Students should take initiative and } \\
\text { be able to engage in activities regardless } \\
\text { of what others might think, which } \\
\text { entails courage and curiosity. }\end{array}$ & $\begin{array}{l}\text { "...try new things and throw themselves } \\
\text { into something, even if you get into the } \\
\text { red zone, as we call it ... So still try to } \\
\text { challenge yourself" }\end{array}$ \\
\hline
\end{tabular}


In the discussion the teachers in general supported all five life skill themes and found them very important for their students. The reason for the teachers' selection of life skills were mostly practical in relation to planning the upcoming lessons, and several teachers were inclined to implement several themes.

Next, the teachers were introduced to the "The Implicit/Explicit Continuum of Life Skills Development and Transfer" (Bean et al., 2018). The model was used as a tool to guide their integration of explicit life skills activities into their teaching practices. It consists of six levels with practical strategies to address life skills development through sport. The sport context, its organisation and rules, form the basis. The second level consists of the positive social climate facilitated by the coach. These two levels belong to the implicit approach but is also fundamental for the explicit approach. The explicit approach involves the next four levels starting with defining, reflecting and discussing life skills in specific sport contexts. This is followed by the fourth level which involves practicing the life skill with subsequent reflections. The last two levels concern transfer and comprises discussing and reflecting then practicing life skills in non-sport settings. The upper levels are dependent on the lower, and the development and transfer of life skills are optimized as coaches move up on the explicit levels (Bean et al., 2018).

The teachers reviewed their lesson plans for the upcoming period and worked on integrating life skills activities in their practice. This work was structured based on four questions derived from The trainer as cultural leader (Henriksen, 2015): Which life skills are important to develop through sport? What specific actions show that students possess the life skill? Which activities could I launch to support the desired actions? And how can I implement the activities into my practice?

\section{3) Implementation phase}

Approximately two weeks after the workshop the teachers implemented the new activities and explicit teaching strategies in their main sport practice. Three consecutive weeks were devoted to the testing of the life skill courses. Following each lesson, the teachers were encouraged to fill in a logbook describing and reflecting on the delivery of the lesson. Furthermore, during the implementation period, the principal researcher visited each school once. Logbooks and school visits were primarily intended to support the teachers' implementation of activities and secondly for the researchers to gain insight into the new practice before the evaluation phase.

\section{4) Evaluation phase}

Shortly after the life skill course, the evaluation phase was completed as the final step in the development program. The teachers participated in focus groups interviews reflecting and discussing both the development and the experiments carried out during their implementation of the life skills course. The aim was to explore the teachers' experiences working explicitly with the students' life skill development and transfer through the main sport. The three focus groups (one at each school) constitute the main empirical material for this study and will be 
presented in the results section. At least two teachers from each main sport participated in the interviews, which were conducted at the schools and lasting approximately 90 minutes. The focus group questions were a mix of specific questions concerning the development program and possibility to discuss and share experiences among the teachers.

The two main areas were: 1) the teachers' experiences with the development program and 2) their experiences with the new practice. Examples of question: "Could you tell me how you experienced the workshop and the process of planning the life skill program?", "Could you describe a main sport class in which you worked with life skills?" and "Transfer is an important part of life skill development, how was your experiences working with that aspect?"

\subsection{Analysis Method}

The interviews were recorded and fully transcribed based on a simple transcription strategy. Analysis was carried out using the six-phased thematic analysis method (Braun, Clarke, \& Weate, 2016). Transcripts were read several times to get a sense of the immediate nature of the data, and notes were added-constituting the preliminary coding of the material. The process of analysis was inductive within the structure of the interview guide. The initial codes were generated in Nvivo12 and subsequently read, compared, refined and systematized manually in an iterative process. Codes were regularly changed and developed as a consequence of a deeper understanding of the empirical material. Furthermore, patterns were sought across the three schools aiming to form more general themes. Transcription and coding were performed independently by the first author, and to ensure coding reliability and accuracy (Barbour, 2001), the other authors read the transcribed interviews and discussed and revised the analyses. During the analytical process, some codes and minor themes were disregarded due to inconsistency or irrelevance to the research question.

\section{Results}

The results are presented in five themes: 1) The new practice, 2) Balancing discussion and practice, 3) Working with transfer, 4) Development of students life skills, and 5) Teacher development program.

\subsection{The New Practice}

The teachers incorporated life skills into the main sport using both discussions, reflections and practice. Common to activities using discussion and reflection-the third and fifth level in the implicit/explicit continuum-are that they engaged students in reflection processes related to the chosen life skill. These processes were carried out either individually, in groups or in plenary. Four of the main sports began the life skill course with an introduction, which focused on creating a common definition and framework of understanding for the students. For example, girls' soccer began with a 20 -minute plenary discussion about 
life skills and how they are to be used in and outside of sport. Fitness and one of the TeamGym (School B) classes used an entire lesson to introduce life skills, as the teachers anticipated life skills as a very new topic for the students. The activities using reflection and dialogue were used throughout the course for several main sports. Typically, in the beginning or ending of a lesson. TeamGym (School A), incorporated mental warm-up, where students in pairs selected two goals for the lessons, which they wrote down and pinned on the blackboard so that it was visible during the lesson. A mental cool-down ended the lessons, in which the teachers facilitated a subjective evaluation of the students' own performance and asked them to reflect on ways to improve.

Two other main sports used individually defined goal setting, where students defined their own goals and followed up several times afterwards. Finally, girls' soccer posed a life skill question at the beginning of the lesson e.g. "how do you feel when you don't succeed?". Students should then focus on the question during the lesson and reflect on their answer before the next lesson, where teachers facilitated an open dialogue and talked about the transfer to other life settings outside sport.

Other activities practiced life skills as part of physical exercises. One main sport working with the theme proactive, developed gravity zoom, where the students worked with courage as a theme, using free fall to the floor as a practical starting point. Another example was in rhythmic gymnastics were the students worked with movement improvisation in relation to a fictive story and thereby promoting initiative and curiosity. One of the TeamGym (School B) classes also worked with the students' creativity and courage focusing on exploring new movements. An example was exploring alternative jumps on the trampette and landing on an unstable surface. In the fitness class, students worked in groups to make different figures, e.g. bicycle, tower and car, when the music stopped. Through various games, they also focused on the students' courage to behave silly together with peers.

Two main sports involved the students in constructing a training station focusing on technical aspects of the sport (TeamGym School A and B). One of the sports focused on curiousness and initiative, while the other sport focused on deliberate practice and planning. Thus, the integrated activities can be used to promote different life skills depending on the focus and framing by the teachers. Deliberate practice was also in focus in the E-sport class, where students scheduled their weekly activities and promoted perseverance by breaking down, practicing and repeating technical game skills and strategies.

The teachers had very good experiences working with the new practice and reported that the students in general were engaged and pleased to participate in the different activities.

"The students have been very positive in the life skills discussions. I don't think we have experienced otherwise" (Female teacher, Girls soccer). "No, in fact, they were almost always engaged when we introduced them to something 
new" (Male teacher, Girls soccer)

All the teachers agreed that a more explicit life skills approach is both relevant and possible to implement into the main sport curriculum. Several of the teachers considered life skills perspectives applicable in most areas of their main sport teaching practice and expressed a high degree of alignment between the theoretical foundations for the life skill course and their current practice. The life skills development program and the life skills courses increased the teacher's awareness of how to incorporate life skills and subsequently opened the door to new and different activities.

\subsection{Balancing Discussion and Practice}

During the evaluation, the balance between discussing life skills and practicing life skills in sports were a key concern for the teachers. Some teachers expressed their scepticism towards working more explicitly with life skills, and they were worried whether they would be spending too much time talking with students instead of being physically active.

"We spent a significant amount of time talking rather than getting started. Sometimes we may well have spent 20 minutes if they also have questions about $i t$, and then time was almost up. (...) considering we have other things to achieve, we spent too much time on it...”. (Male teacher, Girls' soccer)

The teachers perceive the main sport as primarily physically active lessons and talked about finding a "delicate balance" between thinking and doing physical activities. Even though they found life skills important and relevant, they didn't consider it as a core content of the main sport. The teachers expressed difficulties linking more explicit life skills approaches with physical activities in a good way. They were worried that the new practice might seem odd and compromised the main purpose of the activities in the main sport e.g. getting muscles warmed up during warm-up.

"It was like we are warming up-can't we just get the pulse racing by running around. Why shall we do this? "(Male teacher, Fitness)

In general, the main sport is highly prioritized, because it's the main reason many of the students attend the schools. The teachers expressed consideration between the main sport as a learning space and a doing sport space. They were worried that too much focus on developing life skills would reduce the students' motivation and joy if it became too "school-like". One of the teachers described an attempt to talk with students about transferring courage in gymnastics to non-sporting contexts as far away from her normal practice and overly pedagogic.

"As we sat in the circle, we asked the students "where have you taken chances, today? How could you apply this in your everyday lives?' We would NEVER discuss this in a normal training situation. And I thought to myself 'Oh god! How will they perceive it?' Because it sounds all pedagogic to me." (Female teacher, Rhythmic Gymnastics)

Despite these concerns on the use of time and the students' motivation the 
teachers were overall positive towards the discussion activities. They experienced engaged students and that the discussions added a meaningful new perspective to their teaching practice.

\subsection{Working with Transfer}

Working with transfer to non-sporting contexts was the most difficult area for the teachers and they found it less relevant. Some teachers expressed very clearly that they didn't see it as a task for them:

"... the part about discussing and practicing transfer 1 ve very much ignored, because it has frustrated me (...) I don't think we should do that." (Male teacher, TeamGym School A)

Most teachers were reluctant to work explicitly with transfer and believed in an unconscious and implicit transfer. They thought that it is up to the students themselves to determine which life skills they want to obtain and transfer from sports and into other contexts. Additionally, they repeated the argument that the most important focus in the main sport is improving students' sport specific skills.

Some teachers expressed that the transfer is dependent on the non-sporting context and its similarity to the sport context. The main sport teachers articulated transfer of life skills, but they found it challenging and they worried that the students felt it was inappropriate. Many of the teachers chose therefore only to talk about the life skills in connection to the sporting context and deemphasized the aspect of transfer.

Unlike most, the teachers from two main sports were particularly focused on articulating transfer to non-sporting contexts. They used different types of activities, where they asked questions focusing on the students' own reflections on their daily activities, e.g. how are you courageous in main sport and how do you show courage in your everyday life? In that way, the teachers tried different ways to get students themselves to reflect about life skill transfer.

\subsection{Development of Students' Life Skills}

All teachers expressed concerns about the limited duration of the course and the students' life skills development. They generally believe that three weeks is too short to induce sustainable changes, which the quote below illustrates:

"Well $P \mathrm{~m}$ not sure you can speed up the process, either. Now we are just learning some life skills (...) But if we do small things over a longer period-then maybe something will stick." (Male teacher, TeamGym School A)

The teachers believe that the students are able to comprehend the connection between the life skills they worked with in the sport context and how these life skills can be used in non-sport settings. However, they doubt whether this knowledge and reflection will turn into action. They are concerned that the students forget the life skills after the course or that they will not be able to use them in another context. 
Most teachers are aware that the development of life skills is an ongoing process and requires continuing articulation and repetition. Some teachers were confident that the explicit approach will aid the students to act on it later

"But I think transfer will happen. It's just the time scale because if you practice long enough then maybe someday you will be braver e.g. sit by another table. For some the time frame might be half a year and for others it may take years before they actively use the life skills learned in sport into other settings." (Male teacher, TeamGym School A)

Others expressed it in the way that, what they learn now, might not immediately turn into changes in behaviour, but it increases the possibility that it will do so in the future under the right circumstances.

\subsection{Teacher Development Program}

Several of the teachers described the workshop as particularly rewarding for their participation in the project. They found the high degree of involvement meaningful and were pleased to be part of defining, describing and contextualizing relevant life skills and be allowed to choose their own life skills to work with. One teacher described it as follows:

"I think it was very exciting to start out with a broader perspective. Being able to choose something that suited us and which we would like to immerse ourselves in made it quite meaningful and not too difficult to apply in practice." (Male teacher, TeamGym School A)

Thus, the teachers found it easy to develop their individual life skill courses, after the theoretical introduction and participatory approach of defining, describing and contextualizing it into their own practice. Being able to choose one of five defined life skills added to the feeling of autonomy and relevance.

The teachers were happy to work specifically with the development of their own practice, and that the outcome of the development program was a tangible course plan, which decreased the distance from theory to practice. After the workshop several of the teachers had developed complete course plans and expressed to be ready to test the new practice.

Other teachers had to put in extra work between the workshop and the beginning of the course. They had difficulties translating the theory into practice and expressed a need for more time to develop new initiatives. This was especially the case for the teachers, who didn't participate in the first focus group. Some teachers wished for practical examples showing how to integrate life skills into practice.

Several of the teachers found the development program rewarding for their teaching practice. They were inspired to an alternative approach to the main sport, which is expressed below:

"It's the approach. I think I have been inspired by the approach to the main sport. I ve just used our previous practice as a starting point, and then I changed it a little." (Female teacher, Fitness) 
The teachers expressed that the theoretical introduction of life skills, the explicit approach and practical teaching strategies was new and made them reflect upon their current practice. They were inspired to take their main sport teaching practice in new directions and gradually incorporate more and more into their practice. In that way, the program gave the teacher an opportunity to develop their own specific practice, and the theoretical framework helped them define or modify the purpose of previous practice. In that way old activities became more meaningful with a life skill twist.

"... you have a lot of games that you might have used in the past to fill time, but here you could then twist some parameters and make it work to put a life skill into play." (Male teacher, TeamGym School B)

According to the teachers, life skills added an extra dimension to the main sport and facilitated reflection about their own normal practice. It increased their awareness of their practice and helped them revive good practice. Several of the teachers mentioned that they expected to incorporate some of the life skill activities, into their curriculum after this project has ended.

\section{Discussion}

The aim of this study is to present how teachers can be involved in the development of an explicit life skill course and evaluate how this process and the new practice were experienced by the teachers. Overall, the participatory approach was well received by the teachers, and they expressed satisfaction with the close connection to their teaching practice. Their explicit teaching approach comprised both activities focusing on reflection and discussion as well as activities practicing life skills in the main sport. Most teachers were challenged by the explicit transfer dimension, and worried about the balance between time where the students were standing still talking, discussing and reflecting and time with physical activity. Different aspects of the explicit life skill approach and practical teaching strategies are discussed further in the following sections.

\subsection{Relevance and Feasibility of an Explicit Teaching Strategy}

The analysis showed that the teachers believe that sport participation develop the students' life skills almost regardless of organization and teaching strategies. This is in line with findings by Bean and Forneris (2017), which show that sport coaches believe that the development of life skills and transfer to other contexts takes place through the mere participation in sports. This implicit approach is dependent on that the sports participants themselves being able to identify and activate the life skill potentials in sport participation (Camiré \& Kendellen, 2016). The challenge with the implicit approach is that it only provides indirect opportunities for the acquisition of life skills, which might be insufficient and random - and in worst case negative for the students life outside sport (Bean et al., 2018; Gould \& Carson, 2008; Petitpas, Cornelius, Vanraalte, \& Jones, 2005; Pierce et al., 2017). 
Some sports coaches and teachers may have difficulty with an explicit approach because they simply do not have the competencies to initiate such processes (Camiré \& Kendellen, 2016). In the development program the researchers introduced a theoretic rationale for the explicit approach, identified and described relevant life skills and showed avenues as to how they could be translated into practice. The teachers stated that the development program succeeded in creating a practical framework which where relevant and feasible for them. They implemented several elements of the practical teaching strategies in the life skills courses. A reason for this success could be the delimited and targeted theoretical input, which has been underlined as important for coaches' ability to immediately apply the new perspective in practice (Camiré \& Trudel, 2013). Furthermore, the current program and theoretical introduction was based on a thorough scientific research base, which have been shown to increase the likelihood that the life skills activities enhances the actual building of life skills among students (Trottier \& Robitaille, 2014).

The teachers succeeded in moving from an implicit to a more explicit life skills approach. Some activities were integrated into physical activities in the sport, while other were reflexive and discussion based. According to the implicit-explicit-continuum the reflective and discussion-based activities are important for life skill acquisition and transfer. And it has been posited that the strongest impact is achieved when teaching strategies incorporate both practical exercises and life skills talks (Hellison, 2010). However, in general teachers are reluctant to spend too much lesson time on talking.

Some teachers' practical life skill teaching strategies focused primarily on giving the students practical and physical experience with life skills. This may give rise to considerations as to whether the group of students who were mainly exposed to practicing life skills learned enough from the course. Relying solely on practicing life skills overlooks the reflexive component, and it is quite possible that students may not form the foundation for understanding the broader dimensions of the practiced life skills.

\subsection{The Challenging Transfer}

The teachers were reluctant to implement activities aimed at transferring life skills to settings outside the sporting context. Several teachers mentioned that they have not worked with transfer, because they don't want to spend too much time being physical inactive, as they do not perceive it as a primary purpose for their teaching. This is a challenge, as research indicates that even using short debriefings, where students discuss how life skills can be used, increases the likelihood that students will act and thereby achieve a successful transfer (Allen, Rhind, \& Koshy, 2015; Bean, Kendellen, \& Forneris, 2015; Camiré, Forneris, Trudel, \& Bernard, 2011; Pierce et al., 2017).

The challenging task with adopting the explicit approach and transfer may pose a barrier to achieving the benefits of operating at the top explicit levels in the continuum model (Bean et al., 2018). Two groups of teachers deliberately 
implemented questions in relation to the sports activities, which were intended to guide students towards transfer opportunities. The teachers experienced that the students developed a good understanding of the competencies they were presented with during the life skills course and that the students had become more aware of how to use the life skills learned through sport in non-sport contexts. A recent research article reports similar findings from the work with three boxing academies implementing a life skills framework called the Passport to Success for children and young people in the range $9-18$ years old. The young boxers gained understanding of life skills and their transfer only through life skills reflection (Hemphill, Gordon, \& Wright, 2019).

Teachers and coaches at boarding schools, colleges and academies have a unique opportunity to work with transfer through the different contexts of the students' daily lives. In these settings they have access to and responsibility for both the sport and non-sport context in which the students engage in. The teachers in this development program point out that, ideally, all such contexts should be used to ensure optimal and sustainable effect of the life skill focus. The combination of the role as both teacher, coach and student counsellor is a unique position to facilitate transfer of life skills, because they can align their teaching strategies and exemplify life skills from one context to another (Pierce, Erickson, \& Dinu, 2018). Working with life skills in different contexts of the boarding school, was not part of this development program, but one teacher experimented on her own initiative with the transfer to her mathematic lessons. She reported clear potentials and found it rewarding for students to bring life skill dimensions explicitly into another context.

Working across contexts can also decrease the time for discussion during the sport lessons if it is integrated in other contexts of the daily life. The concern of inactivity during sport lessons was a main barrier for implementation of this life skill program. In this way working across contexts could increase the interaction between reflecting and practicing life skills and facilitate the transfer process to other contexts, which are found to maximize students' outcome (Bean et al., 2015; Turnnidge et al., 2014). For the Danish boarding schools, working with life skills is extremely relevant due to their stated purposes of life enlightenment, public enlightenment and democratic education. In other educational and sport context these purposes might be less clear, but it is always relevant and important to give students and athletes the best chance for success in life.

\subsection{Practical Implications, Limitations and Future Directions}

This study has shown how teachers can participate in education development and how an explicit life skill teaching approach can be applied in school sport. This approach to in-service teacher development, which takes offset in current practice and applies a theoretical perspective to enhance a specific outcome, was found valued and appreciated by the teachers. Future development programs in educational settings could be inspired by this approach to convert theory into practice. The explicit approach to life skills development was found relevant, 
beneficial and feasible, and it expanded the teachers' ability to include life skills development into their practice. The current approach was short, extensive and limited to the main sport. Future studies and educational development should experiment with whole-school approaches to enhance positive youth development through school sport over prolonged periods.

We recognize that this study has clear limitations. Firstly, the study is almost solely based on focus groups with the participating teachers. This leads to a focus limited to the respondents' subjective experiences and reflections on the life skills course. Logbooks and visits at the schools was conducted, but not included in the analyses. More systematic participant observations could have given further insight into how teachers actually implemented the life skills approach, and which strategies were carried out, and how discussion and practice were aligned. Furthermore, interviewing the students would have provided additional perspective on the teachers concerns and additional insight into the life skill development process.

Behavioural changes take time and so do changes to teaching practices. The duration and intensity of a developmental program can influence whether teachers become comfortable incorporating an explicit life skills approach into their practice (Gould, Damarjian, \& Medbery, 1999). To increase the possibility of a lasting change in teaching practice it would have been beneficial to conduct further iterations with the teachers and include other life skills or expanding the approach to other contexts at the boarding schools. More workshops, where teachers-building on their initial practical experiences and challenges with the life skills course-could plan new courses, strategies and activities, could have increased the possibility of a higher degree of internalization of the explicit approach in their practices.

\section{Conclusion}

This study has developed and evaluated a participatory action research program promoting life skills development and transfer through sport participation at three Danish boarding schools. The teachers were co-creators of a life skill course and gained experience with explicit teaching strategies on how to promote development of life skills through sport. These strategies included discussing, reflecting and practicing life skills. Some teachers invented new activities and other modified current activities with the new focus. In general, the teachers agreed that the new practice can promote the development of life skills, but some were challenged by spending too much time on reflection and discussion and worried that it could reduce the students' motivation. Several teachers found it less relevant and inappropriate to work with transfer to non-sport context in the course. Overall, the teachers are convinced that students have improved their understanding of the particular life skill, but uncertain about the students' abilities to remember and transfer the skills to other contexts. They concur that the development of life skills is an ongoing process and requires ongoing articulation, repetition and practice in multiple contexts. 


\section{Acknowledgements}

The authors sincerely appreciate the participation, effort and support from the three schools, teachers and students involved. Furthermore, we acknowledge the Faculty of Health Sciences at University of Southern Denmark for the scholarship to support to the undergraduate research program for Julie Vang Knudsen.

\section{Conflicts of Interest}

The authors declare no conflicts of interest regarding the publication of this paper.

\section{References}

Allen, G., Rhind, D., \& Koshy, V. (2015). Enablers and Barriers for Male Students Transferring Life Skills from the Sports Hall into the Classroom. Qualitative Research in Sport, Exercise and Health, 7, 53-67. https://doi.org/10.1080/2159676X.2014.893898

Barbour, R. S. (2001). Checklists for Improving Rigour in Qualitative Research: A Case of the Tail Wagging the Dog? BMJ, 322, 1115-1117.

https://doi.org/10.1136/bmj.322.7294.1115

Bean, C., \& Forneris, T. (2016). Examining the Importance of Intentionally Structuring the Youth Sport Context to Facilitate Positive Youth Development. Journal of Applied Sport Psychology, 28, 410-425. https://doi.org/10.1080/10413200.2016.1164764

Bean, C., \& Forneris, T. (2017). Is Life Skill Development a By-Product of Sport Participation? Perceptions of Youth Sport Coaches. Journal of Applied Sport Psychology, 29, 234-250. https://doi.org/10.1080/10413200.2016.1231723

Bean, C., Kendellen, K., \& Forneris, T. (2015). Moving beyond the Gym: Exploring Life Skill Transfer within a Female Physical Activity-Based Life Skills Program. Journal of Applied Sport Psychology, 28, 274-290. https://doi.org/10.1080/10413200.2015.1124155

Bean, C., Kramers, S., Forneris, T., \& Camiré, M. (2018). The Implicit/Explicit Continuum of Life Skills Development and Transfer. Quest, 70, 456-470.

https://doi.org/10.1080/00336297.2018.1451348

Bradbury, H. (2015). Introduction: How to Situate an Define Action Research. In H. Bradbury (Ed.), The Sage Handbook of Action Research (3rd ed.). London: Sage Publications.

Braun, V., Clarke, V., \& Weate, P. (2016). Using Thematic Analysis in Sport and Exercise Research. In B. Smith, \& A. C. Sparkes (Eds.), Routledge Handbook of Qualitative Research in Sport and Exercise (pp. 191-205). London: Routlegde.

Camiré, M., \& Kendellen, K. (2016). Coaching for Positive Youth Development in High School Sport. In N. L. Holt (Ed.), Positive Youth Development through Sport (2nd ed., pp. 126-136). London: Routledge. https://doi.org/10.4324/9781315709499-11

Camiré, M., \& Trudel, P. (2013). A Case Study of a High School Sport Program Designed to Teach Athletes Life Skills and Values. The Sport Psychologist, 27, 188-200. https://doi.org/10.1123/tsp.27.2.188

Camiré, M., Forneris, T., Trudel, P., \& Bernard, D. (2011). Strategies for Helping Coaches Facilitate Positive Youth Development Through Sport. Journal of Sport Psychology in Action, 2, 92-99. https://doi.org/10.1080/21520704.2011.584246

Camiré, M., Trudel, P., \& Forneris, T. (2009). High School Athletes' Perspectives on Support, Communication, Negotiation and Life Skill Development. Qualitative Research in Sport and Exercise, 1, 72-88. https://doi.org/10.1080/19398440802673275 
Coghlan, D., \& Brannick, T. (2010). Doing Action Research in Your Own Organisation (3rd ed.). London: SAGE.

Danish, S., Forneris, T., Hodge, K., \& Heke, I. (2004). Enhancing Youth Development through Sport. World Leisure Journal, 46, 38-49.

https://doi.org/10.1080/04419057.2004.9674365

Efterskoleforeningen (2017). The Danish Efterskole 2020 (19/6).

https://www.efterskolerne.dk/-/media/Efterskole/Om-efterskolen/English/Folder UK web.pdf?la $=$ en \&hash $=34836002691$ B13BD63CBBB7DE52C5B0F

Gould, D., \& Carson, S. (2008). Life Skills Development through Sport: Current Status and Future Directions. International Review of Sport and Exercise Psychology, 1, 58-78. https://doi.org/10.1080/17509840701834573

Gould, D., Damarjian, N., \& Medbery, R. (1999). An Examination of Mental Skills Training in Junior Tennis Coaches. Sport Psychologist, 13, 127-142.

https://doi.org/10.1123/tsp.13.2.127

Graham, I. D., Logan, J., Harrison, M. B., Straus, S. E., Tetroe, J., Caswell, W., \& Robinson, N. (2006). Lost in Knowledge Translation: Time for a Map? Journal of Continuing Education in the Health Professions, 26, 13-24.

https://doi.org/10.1002/chp.47

Hellison, D. R. (2010). Teaching Personal and Social Responsibility through Physical Activity. Champaign, IL: Human Kinetics.

Hemphill, M. A., Gordon, B., \& Wright, P. M. (2019). Sports as a Passport to Success: Life Skill Integration in a Positive Youth Development Program. Physical Education and Sport Pedagogy, 24, 390-401. https://doi.org/10.1080/17408989.2019.1606901

Henriksen, K. (2015). Træneren som kulturel leder: Bæredygtig sportspsykologi for unge talenter. In N. N. Rossing, K. Ryom, \& K. Henriksen (Eds.), Talent udvikling i sport: Reflekterende organisationer, gode teams og stærke atleter (pp. 20-35). Aalborg: Aalborg Universitetsforlag.

Holt, N. L., Neely, K. C., Slater, L. G., Camiré, M., Côté, J., Fraser-Thomas, J., Tamminen, K. A. et al. (2017). A Grounded Theory of Positive Youth Development through Sport Based on Results from a Qualitative Meta-Study. International Review of Sport and Exercise Psychology, 10, 1-49. https://doi.org/10.1080/1750984X.2016.1180704

Jacobs, J. M., \& Wright, P. M. (2018). Transfer of Life Skills in Sport-Based Youth Development Programs: A Conceptual Framework Bridging Learning to Application. Quest, 70, 81-99. https://doi.org/10.1080/00336297.2017.1348304

Jones, M. I., \& Lavallee, D. (2009). Exploring Perceived Life Skills Development and Participation in Sport. Qualitative Research in Sport and Exercise, 1, 36-50. https://doi.org/10.1080/19398440802567931

Kemmis, S., McTaggart, R., \& Nixon, R. (2014). The Action Research Planner. Singapore: Springer. https://doi.org/10.1007/978-981-4560-67-2

Lehmann, S. (2018). Aktionsforskning skaber løsninger i praksis. Kbh.: Hans Reitzel.

Petitpas, A., Cornelius, A., Vanraalte, J., \& Jones, T. (2005). A Framework for Planning Youth Sport Programs That Foster Psychosocial Development. The Sport Psychologist, 19, 63-80. https://doi.org/10.1123/tsp.19.1.63

Pierce, S., Erickson, K., \& Dinu, R. (2018). Teacher-Coaches' Perceptions of Life Skills Transfer from High School Sport to the Classroom. Journal of Applied Sport Psychology, 31, 451-473. https://doi.org/10.1080/10413200.2018.1500402

Pierce, S., Gould, D., \& Camiré, M. (2017). Definition and Model of Life Skills Transfer. International Review of Sport and Exercise Psychology, 10, 186-211.

https://doi.org/10.1080/1750984X.2016.1199727 
Trottier, C., \& Robitaille, S. (2014). Fostering Life Skills Development in High School and Community Sport: A Comparative Analysis of the Coach's Role. The Sport Psychologist, 28, 10-21. https://doi.org/10.1123/tsp.2012-0094

Turnnidge, J., Côté, J., \& Hancock, D. J. (2014). Positive Youth Development from Sport to Life: Explicit or Implicit Transfer? Quest, 66, 203-217. https://doi.org/10.1080/00336297.2013.867275

UNICEF (2019). Definition of Terms. https://www.unicef.org/lifeskills/index 7308.html 